\title{
Comparative analysis of the videothoracoscopic interventions results
}

\author{
Otabek Djurayevich ESHONKHODJAEV ${ }^{1 \ltimes \bowtie}$, Ravshan Aliyevich IBADOV ${ }^{1}$, Ulugbek Nasirovich BOBAYEV ${ }^{2}$ \\ and Bakhodir Abdimusayevich ISMAILOV ${ }^{1}$ \\ ${ }^{1}$ Republican Specialized Scientific and Practical Medical Center of Surgery named after Academician V.Vakhidov, Tashkent, Uzbekistan \\ ${ }^{2}$ Andijan State Medical Institute, Andijan, Uzbekistan \\ Corresponding author's Email: dr.sardor.ibragimov@gmail.com
}

\section{ABSTRACT}

Aim. This study was done to determine the feasibility and effectiveness of the proposed method of thoracoscopic hemostasis and aerostasis. Methods. The study included 85 patients operated for bullous lung disease, closed chest injury and penetrating chest wounds in the Lung and Mediastinum surgery department of the Republican Specialized Scientific and Practical Medical Center of Surgery named after Academician V.Vakhidov for the period from 2015 to 2019. Total of 33 patients made up the main group: thoracoscopy using the proposed technique and 52 patients for the comparison group: thoracoscopic aerostasis was performed using known methods. In 21 (40.4\%) cases of comparison group, we performed video-assisted thoracoscopic (VATS) excision and suturing with pleurodesis; in 14 (26.9\%) cases - VATS with stitching of a lung wound. VATS excision and flashing of bullae of the lung using a stapler was performed in $19.2 \%$ (10 of 52) cases of the comparison group and $24.2 \%$ in the main group, where all VATS were supplemented with Geprotsel gel application. Results. Using the Geprotsel in VATS interventions allowed to reduce the necessity of lung tissue stitching from $67.7 \%$ to $27.3 \%$, respectively, to limit excision in $36.4 \%$ of patients, to achieve complete tightness after hardware stitching $\left(\chi^{2}-17.304 ; \mathrm{Df}=3 ; \mathrm{p}<0.001\right)$, which generally leveled the risk of postoperative pneumonia and impaired hemostasis. Recommendation. We suggest that applying Geprotsel gel during VATS for lung tissue damages allows to reduce the application of additional sutures, improve the efficiency of minimally invasive operations with a decrease in the frequency of postoperative disorders of

\section{Original Article}

PII: S225199392000002-10

Rec. 05 January 2020

Rev. 15 March 2020

Pub. 25 March 2020

\section{Keywords}

Lung Pathology,

Video-Assisted

Thoracoscopy,

Geprotsel,

Hemostasis,

Aerostasis aero- and hemostasis.

\section{INTRODUCTION}

The number of complications in thoracoscopic lung surgery associated with the development of postoperative intrapleural bleeding and leakage of the pulmonary parenchyma, as well as with a violation of the tightness of the sutured bronchus stump, remains significant and does not have a noticeable downward trend [1]. Under conditions of persistent pneumothorax, prerequisites are created for the development of infectious complications, the formation of a persistent residual cavity, which, in turn, may require repeated interventions or prolonged drainage [2].

Some studies showed that air leakage occurs immediately after surgery in 28-60\% of patients who undergo conventional lung resections, including lobectomy and smaller resections [3]. On the $1^{\text {st }}$ day after surgery, air leakage is observed in $26-48 \%$ of patients; on the 2nd day, air leakage is present in $22-24 \%$ of cases; on the 4th day - in $8 \%$ of cases [4]. The National Emphysema Treatment Trial assumes that air leakage occurs at some point in the postoperative period in 90\% of patients undergoing bilateral procedures with both thoracotomy and thoracoscopy, with average air leak duration of 7 days, and $12 \%$ of patients had a constant air leak even 30 days after surgery $[5,6]$.

To achieve adequate hemoaerostasis - reliable sealing of the resection line - various methods of strengthening the wound surfaces of the lung are used in clinical practice: laser exposure, plasma factors, ultrasound, electrical coagulation, applying synthetic and biological adhesives to the surgical wound, application of adhesive collagen plates and synthetic materials $[7,8]$.

This study aimed to determine the feasibility and effectiveness of the proposed method of thoracoscopic hemostasis and aerostasis. 
The study included 85 patients operated in the Lung and Mediastinum surgery department of the Republican Specialized Scientific and Practical Medical Center of Surgery named after Academician V.Vakhidov (Tashkent, Uzbekistan) for the period from 2015 to 2019. Total of 33 patients of whom made up the main group (thoracoscopy using the proposed technique) and 52 patients considered as the comparison group (thoracoscopic aerostasis was performed using known methods).

The study included patients with the following nosologies: bullous lung disease was diagnosed in $62.4 \%$ of cases, closed chest injury - $21.2 \%$, penetrating chest wounds - $16.5 \%$ of cases.

Surgery was performed as the main treatment. Video-assisted thoracoscopic (VATS) excision and suturing with pleurodesis was performed in most cases of comparison group (40.4\%; 21 out of 52$)$. The next most frequent surgical intervention was VATS with stitching of a lung wound (26.9\%; 14 out of 52). VATS excision and flashing of bullae of the lung using a stapler was performed in $19.2 \%$ (10 of 52) cases of the comparison group and $24.2 \%$ in the main group, where all VATS were supplemented with Geprotsel gel application. The following operations were also performed in the main group: VATS excision of bullae of the lung with application of Geprotsel gel [9] (24.2\%), VATS with application of Geprocel gel on the wound of the lung (21.2\%)

\section{Ethical approval}

The review board and ethics committee of RSCS named after acad. V.Vakhidov approved the study protocol and informed consents were taken from all the participants.

\section{Statistical analysis}

The obtained results were subjected to the statistical processing with the using the standard package of Microsoft Excel 2010 software by the method of variation statistics with the estimation of indexes' values $(\mathrm{M} \pm \mathrm{m})$.

\section{RESULTS AND DISCUSSION}

The most frequent complications of VATS were hemostasis and aerostasis disorders and, as a result, recondensing hemothorax and pneumothorax. Comparative analysis of complications frequency after VATS in comparison groups is presented in Table 1. Thus, at the comparative analysis of the complications frequency after VATS it was noted that only 3 (5.8\%) patients of the control group had a recurrence of bleeding, while one of them had a recurrence of hemothorax (1.9\%). Violations of aerostasis were registered in one (3.0\%) case in the main group patient and in 6 (11.5\%) patients from the comparison group. Pneumothorax relapse was only reported in one (1.9\%) patient from the comparison group.

Exudative pleuritis was also observed only in $3(5.8 \%)$ patients from the comparison group. Thus, the frequency of complicated course in the control group significantly exceeded these parameters in the main group (9 vs. 1) with the difference reliability (criterion $\chi^{2}$ ) - 3,964; $D f=1 ; P=0.047$.

Table 1. The comparative analysis of complications rate after VATS

\begin{tabular}{lcccc}
\hline \multirow{2}{*}{ Complication } & \multicolumn{2}{c}{ Main group } & \multicolumn{3}{c}{ Comparison group } \\
\cline { 2 - 5 } & abs. & $\%$ & \multicolumn{2}{c}{ abs. } \\
\hline Impaired hemostasis & 0 & $0.0 \%$ & 3 & $5.8 \%$ \\
Impaired aerostasis & 1 & $3.0 \%$ & 6 & $11.5 \%$ \\
Pneumothorax relapse & 0 & $0.0 \%$ & 1 & $1.9 \%$ \\
Hemothorax relapse & 0 & $0.0 \%$ & 1 & $1.9 \%$ \\
Exudative pleuritis & 0 & $0.0 \%$ & 3 & $5.8 \%$ \\
Total number of patients with complications & 1 & $3.0 \%$ & 9 & $17.3 \%$ \\
\hline
\end{tabular}

Criterion $\chi^{2} 3.964 ; \mathrm{Df}=1 ; \mathrm{P}=0.047$

Out of 31 patients with bulla in the comparison group, a bulla rupture less than $5 \mathrm{~cm}$ occurred in 21 patients and 10 patients with bulla were over $5 \mathrm{~cm}$ in size. At the same time, pneumonia after aerostasis was noted in 4 (12.9\%), 2 (9.5\%) with bull less than $5 \mathrm{~cm}$ and 2 (20.0\%) with bull more than $5 \mathrm{~cm}$. In the main group of this type of complication in 22 patients ( 8 patients with bulla more than $5 \mathrm{~cm}$ and 14 patients with bulla less 
than $5 \mathrm{~cm}$ ) with bull disease was not noted (criterion $\chi^{2}-3.918 ; \mathrm{Df}=1 ; \mathrm{P}=0.048$ ). Hemostasis disorder was noted in only one (10\%) patient from the comparison group with a bulla size greater than $5 \mathrm{~cm}$.

When considering the technical aspects of HTS performance at the break of the bulla (Figure 1), it was noted that the use of gel composite material allowed in $36.4 \%$ of cases in the main group to limit the bulla excision without piercing the wound surface, while in the comparison group in $67.7 \%$ of cases the bulla excision was necessarily complemented by piercing the wound surface. Sealed hardware piercing was practically comparable in the comparison groups and was required in $8(36.4 \%)$ cases in the main group and in 8 (25.8\%) comparison groups. Additional sewing after the mechanical stitching was performed in two (6.5\%) patients from the comparison group.

The next comparative analysis in the compared groups depending on the reason for which VATS interventions were performed was the analysis of treatment results in case of lung injury (Figure 2). So, from 11 patients of the main group after VATS, in one case (9.1\%) there was a pneumonia and there were no cases of hemostasis disturbance, whereas, from 21 patients of the comparison group in 2 cases there was a pneumonia (9.5\%) and in 2 cases (9.5\%) hemostasis disturbance.

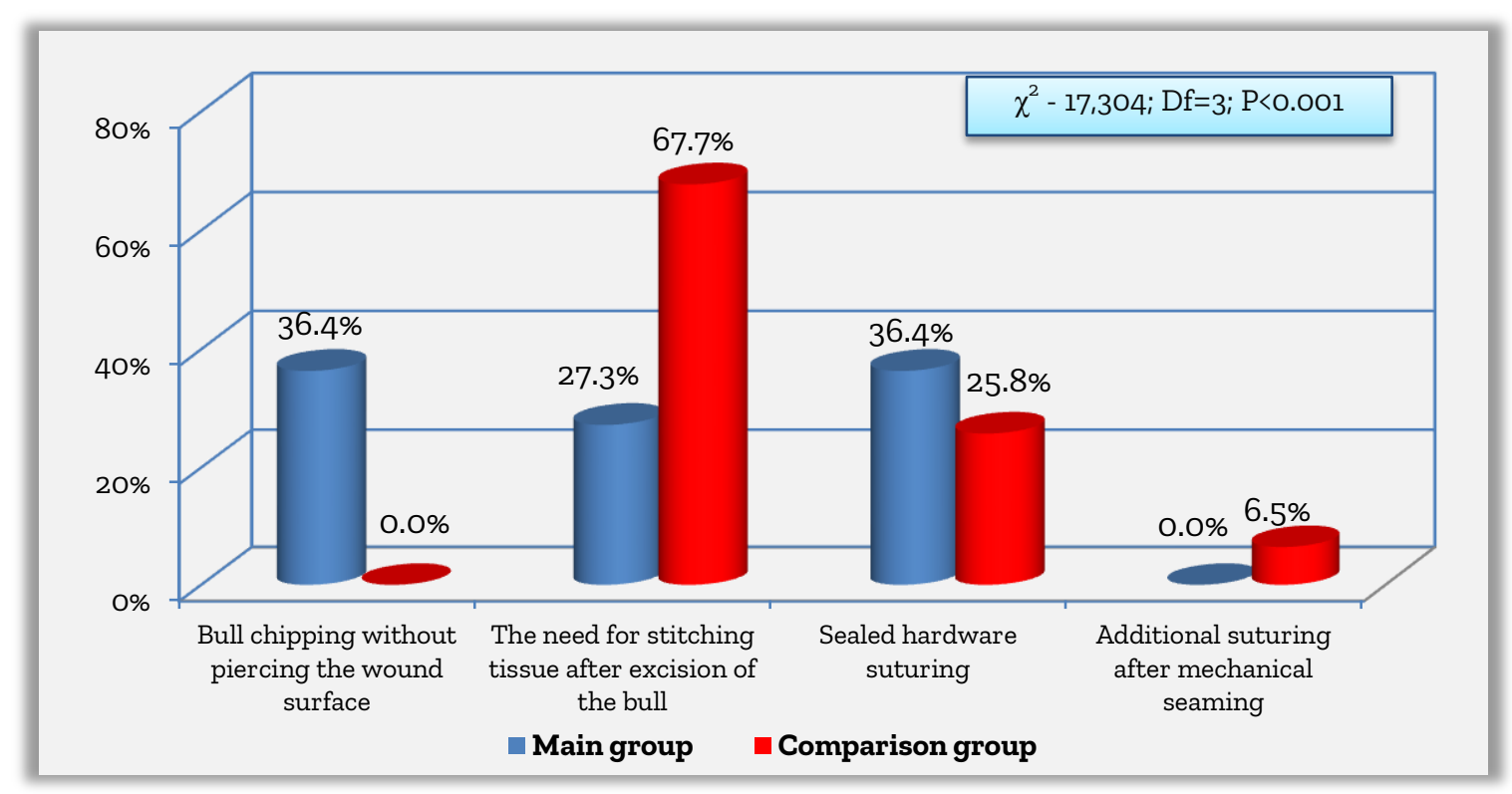

Figure 1. Technical aspects of VATS Interventions for pulmonary rupture

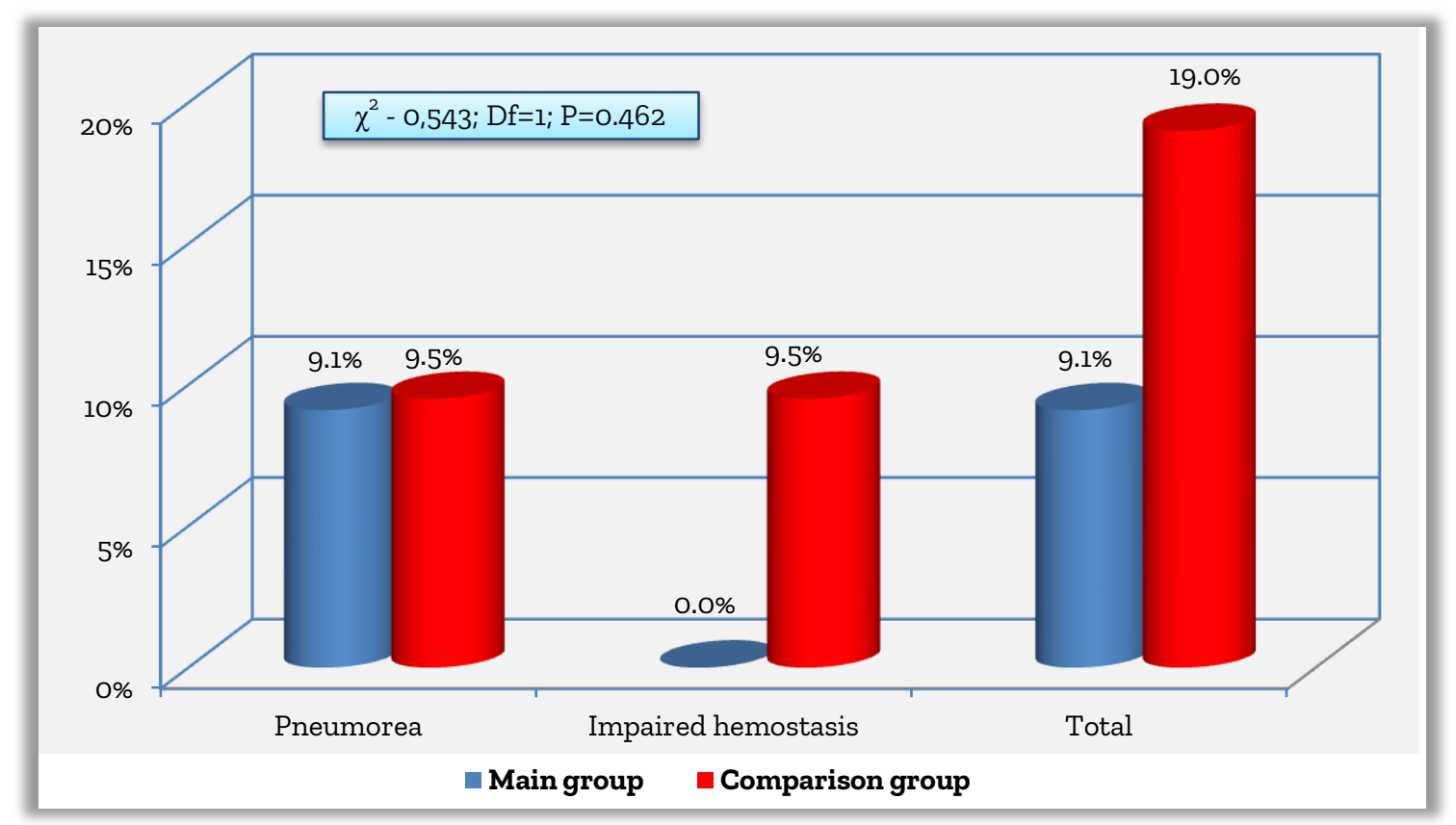

Figure 2. The frequency of complications after VATS interventions for lung injury 
When considering the technical aspects of VATS in the lung injury (Figure 3), it was noted that in $36.4 \%$ of cases in the main group the use of gel composite material allowed achieving good results without piercing the wound surface, while in the comparison group in 33.3\% of patients the effectiveness of hemostasis and aerostasis was achieved by electrocoagulation. Hermetic suturing of the lung wound was practically comparable in the comparison groups and was required in 6 (54.5\%) cases in the main group and in 10 (47,6\%) cases in the comparison group. Additional suturing after mechanical suturing was performed in one (9.1\%) patient from the main group and in 4 (19.0\%) patients from the comparison group.

One of the evaluation criteria that determine not only the effectiveness of manipulations with VTS interventions, but also the quality of life of the patient is the duration of drainage of the pleural cavity and drainage.

Table 2 shows the duration of pleural cavity drainage in comparable groups. Thus, during two days the pleural cavity drainage was required in 31 (93.9\%) patients of the main group and in 42 (80.8\%) patients from the comparison group. The pleural cavity drainage was required for three days in 1 (3.0\%) patient from the main group and in 1 (1.9\%) patient from the comparison group. From 4 to 5 days and from 6 to 7 days drainage was observed only in the comparison group patients: 4 (7.7\%) and $3(5.8 \%)$ patients, respectively. Drainage was prescribed for $2(3.8 \%)$ patients from the comparison group.

Summary results of VATS interventions in comparison groups are presented in Fig. 4. As can be seen from the diagram, complications were noted in only $3.0 \%$ of patients in the main group versus $17.3 \%$ in patients from the comparison group; pleural puncture (1.9\%) and thoracoscopy for hemothorax (1.9\%) were required only in patients of the comparison group. Only patients (3.8\%) from the comparison group were also discharged with drainage.

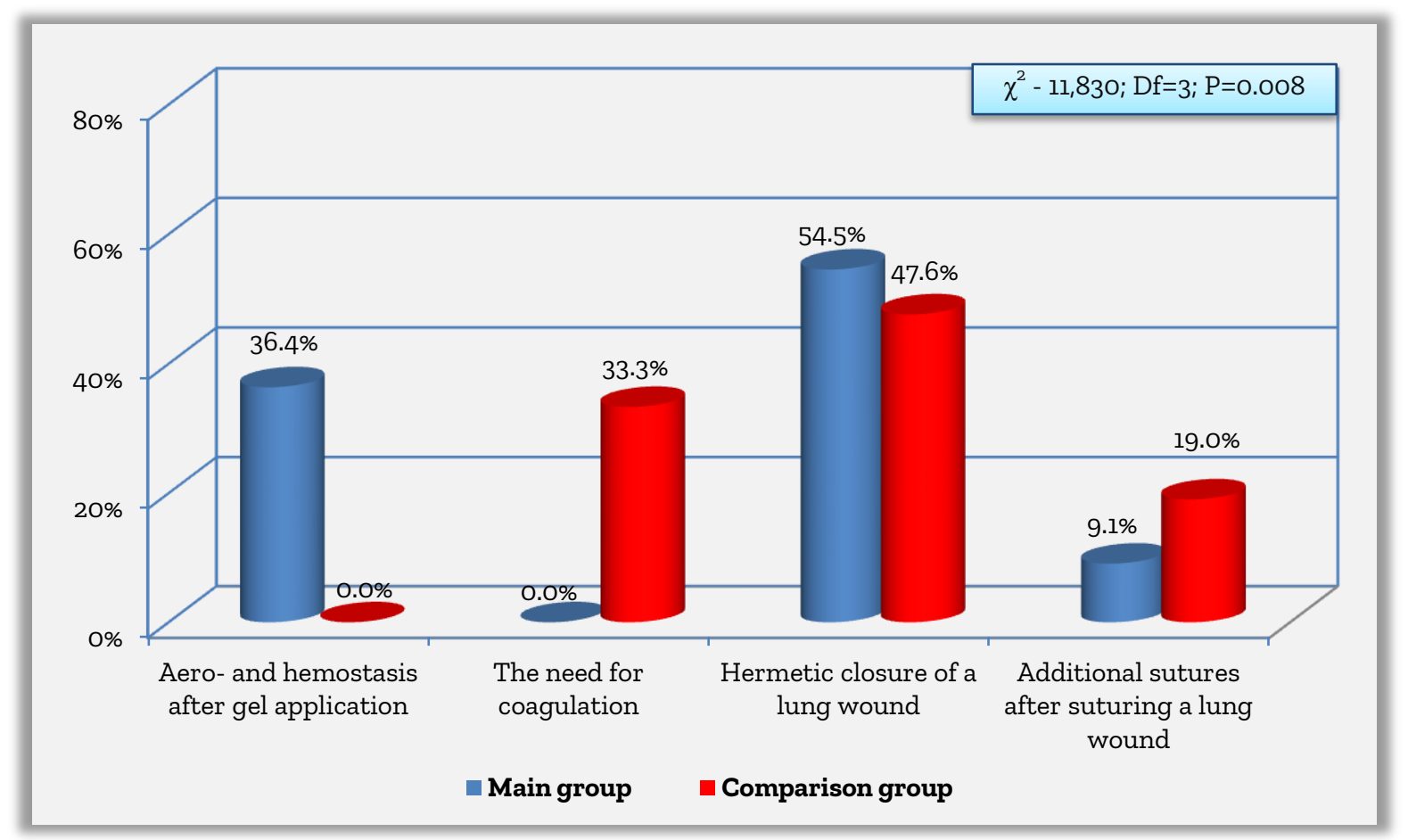

Figure 3. Technical aspects of VATS interventions for lung injury

Table 2. Duration of pleural cavity drainage

\begin{tabular}{lcccc}
\hline \multirow{2}{*}{ Drainage dates } & \multicolumn{2}{c}{ Main group } & \multicolumn{2}{c}{ Comparison group } \\
\cline { 2 - 5 } & abs. & $\%$ & abs. & $\%$ \\
\hline 2 days & 31 & $93.9 \%$ & 42 & $80.8 \%$ \\
3 days & 1 & $3.0 \%$ & 1 & $1.9 \%$ \\
4-5 days & 1 & $3.0 \%$ & 4 & $7.7 \%$ \\
6-7 days & 0 & $0.0 \%$ & 3 & $5.8 \%$ \\
Discharged with drainage & 0 & $0.0 \%$ & 2 & $3.8 \%$ \\
Total & 33 & $100.0 \%$ & 52 & $100.0 \%$ \\
\hline
\end{tabular}




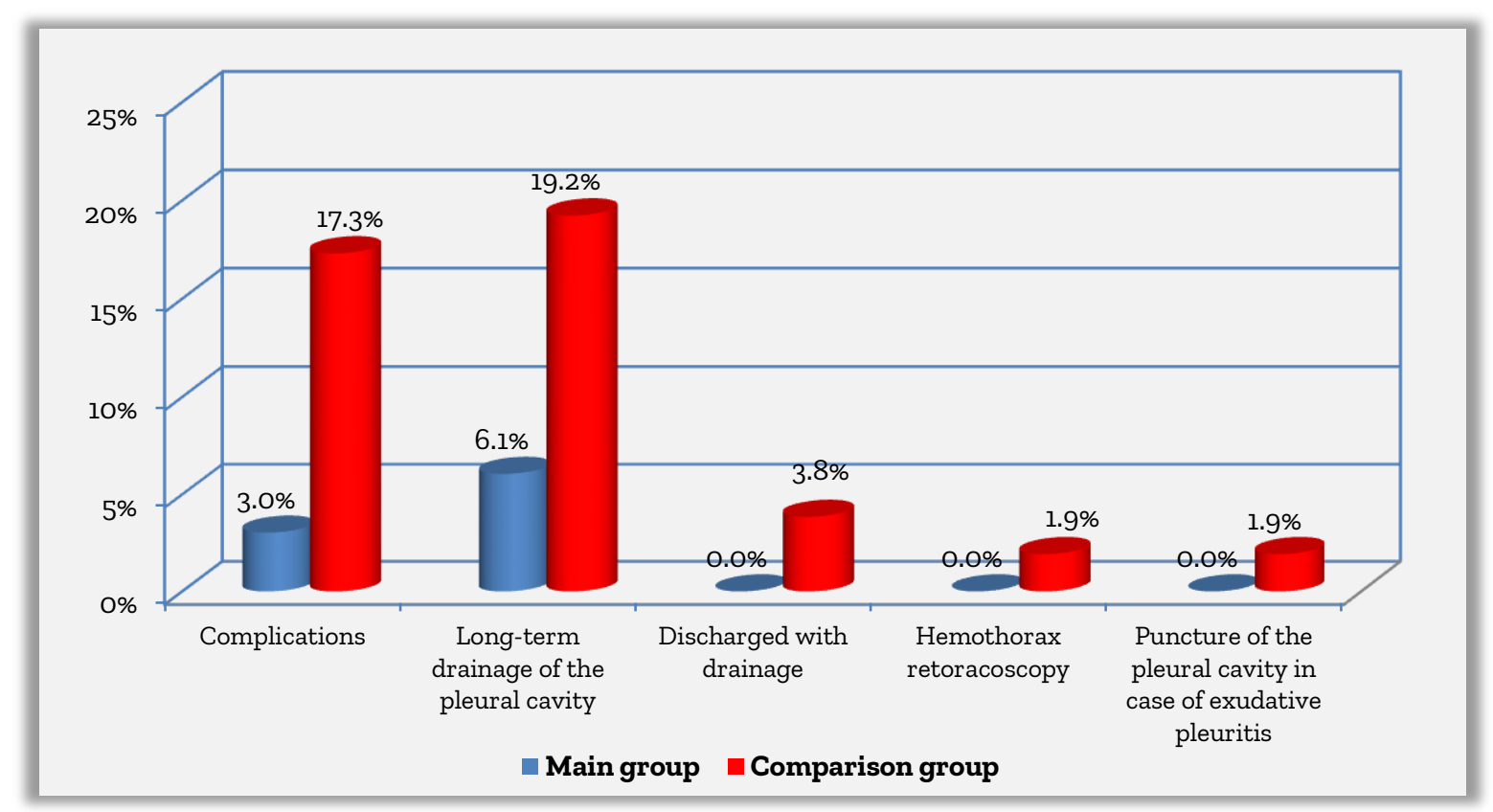

Figure 4. Results of VATS interventions

\section{CONCLUSION}

The use of Geprocel gel during VATS interventions reduced the need for flashing of lung tissue after excision from $67.7 \%$ to $27.3 \%$, respectively, limited to excision in $36.4 \%$ of patients, to achieve complete tightness after hardware flashing $\left(\chi^{2}-17.304 ; \mathrm{Df}=3 ; \mathrm{p}<0.001\right)$, which generally ensured the risk of postoperative pneumorrhea and hemostasis, reducing the overall frequency of all complications from $16.1 \%$ to $0 \%\left(\chi^{2}-3.918 ; D f=1 ; p=0.048\right)$. In case of wound damage of the lung tissue application of the composite material in the form of gel in the course of VATS interventions allows to improve the tightness of primary sutures from $71.4 \%$ to $85.7 \%$, respectively, to reduce the probability of additional sutures from $28.6 \%$ to $14.3 \%$, and in general to improve the efficiency of mini-invasive operations with a decrease in the frequency of postoperative manifestations of air and hemostasis abnormalities from $19.0 \%$ to $9.1 \%$. The developed of VATS-technique for aero- and hemostasis abnormalities in case of pulmonary tissue injuries by means of local application of composite material in the form of a gel by means of the suggested delivery device allowed to reduce the frequency of the mentioned complications in the postoperative period from 17.3\% to 3.0\%, to reduce the necessity of prolonged drainage of the pleural cavity from $19.2 \%$ to $6.1 \%$, to level out the necessity of repeated mini-invasive manipulations (3.8\% in the comparison group) and, accordingly, to increase the share of patients without complications.

\section{DECLARATIONS}

\section{Acknowledgements}

This work was supported by "Republican Specialized Scientific and Practical Medical Center of Surgery named after Academician V.Vakhidov", Uzbekistan.

\section{Authors' contributions}

All authors contributed equally to this work.

\section{Competing interests}

The authors declare that they have no competing interests.

\section{REFERENCES}

1. Bharat A, Graf N, Mullen A, Kanter J, Andrei AC, Sporn PH, DeCamp MM, Sznajder JI. Pleural hypercarbia after lung surgery is associated with persistent alveolopleural fistulae. Chest. 2016; 149(1):220-7. DOI: https://doi.org/10.1378/chest.15-1591 Google Scholar 
2. Hrachovinová I. Diagnostic strategies in disorders of hemostasis. Diagnostika poruch hemostázy. Vnitrni lekarstvi. 2018; 64(5):537-544. Google Scholar PMID: 30193524

3. Gilbert S, Maghera S, Seely AJ, Maziak DE, Shamji FM, Sundaresan SR, Villeneuve PJ. Identifying patients at higher risk of prolonged air leak after lung resection. The Annals of thoracic surgery. 2016; 102(5):1674-9. DOI: https://doi.org/10.1016/j.athoracsur.2016.05.035 Google Scholar

4. Murakami J, Ueda K, Tanaka T, Kobayashi T, Hamano K. Grading of emphysema is indispensable for predicting prolonged air leak after lung lobectomy. The Annals of thoracic surgery. 2018; 105(4):1031-7. DOI: https://doi.org/10.1016/j.athoracsur.2017.11.053 Google Scholar

5. Nishida T, Mikami I, Fujii Y. New technique to prevent prolonged air leak: use of 'Tachosuture'technique. General thoracic and cardiovascular surgery. 2017; 65(2):133-136. DOI: https://doi.org/10.1007/s11748-016-0733-1 Google Scholar

6. Zhang Q, Qi C, Wang H, Xiao X, et al. Biocompatible and degradable Bletilla striata polysaccharide hemostasis sponges constructed from natural medicinal herb Bletilla striata. Carbohydrate Polymers. 2019; 226:115304. DOI: https://doi.org/10.1016/j.carbpol.2019.115304 Google Scholar

7. Assmann A, Vegh A, Ghasemi-Rad M, Bagherifard S, Cheng G, Sani ES, Ruiz-Esparza GU, Noshadi I, Lassaletta AD, Gangadharan S, Tamayol A. A highly adhesive and naturally derived sealant. Biomaterials. 2017; 140:115-27. DOI: https://doi.org/10.1016/j.biomaterials.2017.06.004 Google Scholar

8. Hamzah AA, Adnan AS, Rahman MN, Khan AH. Oxidized Cellulose (Surgicel) As a Surgical Hemostat in Liver Injury: A Case Report and Litrature Review. International Journal of Surgical Research. 2013; 2(3):21-3. Google Scholar

9. Khudaybergenov ShN, Eshonkhodjaev OD, and Khalmuratova MK Geprotsel, biocompatible implant: comparative estimation of its application results for providing airstasis and hemostasis in the lung surgery. Journal of Life Science and Biomedicine. 2019; 9(2): 45-51; www.jlsb.science-line.com Google Scholar 